\title{
Development of reverse phase high- performance liquid chromatographic method for the estimation of HIV non- nucleoside reverse transcriptase inhibitor drug efavirenz in the rat brain
}

\author{
Smita Prakash Kakad ${ }^{*}$ and Sanjay Jayprakash Kshirsagar
}

\begin{abstract}
Background: The brain is the potential viral reservoir, and estimating the antiviral drug concentration in the brain is a hurdle to the researchers as very few animal models are available for this study. The objective of the study was to develop and validate the RP-HPLC method for the estimation of antiviral drug efavirenz (EFV) in the brain of healthy Wistar rats. EFV was the first-line antiretroviral medication. The optimized HPLC condition used for the analysis had the mobile phase methanol to water (9:1) ratio. The flow rate was set at $0.8 \mathrm{~mL} / \mathrm{min}$, while the detection wavelength was $248 \mathrm{~nm}$.
\end{abstract}

Results: The retention time was found to be $5.7 \mathrm{~min}$, and the \% RSD was found within the limit. Recovery was found to be nearly $78 \%$. The validation results were found to be within the limit range; hence, the obtained method was accurate, specific, rapid, and repeatable for estimation of EFV in the brain.

Conclusion: This method for estimation of EFV in the rat brain can be applicable for pharmacokinetic and toxicology study of EFV in the brain after administration of EFV to rats.

Keywords: Efavirenz, HPLC, Brain pharmacokinetic

\section{Background}

Efavirenz (EFV) is an antiretroviral drug classified as non-nucleoside reverse transcriptase inhibitors (NRTI). It is one of the first-line agents in HIV-1 therapy [1]. Chemically, it is (S)-6-chloro-(cyclopropylethynyl)1,4dihydro-4-(trifluoromethyl)-2H-3,1-benz-oxazin-2-one.

The empirical formula for the same is $\mathrm{C}_{14} \mathrm{H}_{9} \mathrm{ClF}_{3} \mathrm{NO}_{2}$, and it is practically water-insoluble [2]. The structure of EFV is shown in Fig. 1.

During HIV infection, the sensory neuropathy is one of the major causes of morbidity; toxic effects of

\footnotetext{
* Correspondence: smitadarade87@gmail.com

M.Pharm Pharmaceutics, Department of Pharmaceutics, MET Institute of

Pharmacy, Nashik, affiliated to Savitribai Phule Pune University, Pune,
}

Maharashtra 422003, India

\section{Springer Open}

(๑) The Author(s). 2021 Open Access This article is licensed under a Creative Commons Attribution 4.0 International License, which permits use, sharing, adaptation, distribution and reproduction in any medium or format, as long as you give appropriate credit to the original author(s) and the source, provide a link to the Creative Commons licence, and indicate if changes were made. The images or other third party material in this article are included in the article's Creative Commons licence, unless indicated otherwise in a credit line to the material. If material is not included in the article's Creative Commons licence and your intended use is not permitted by statutory regulation or exceeds the permitted use, you will need to obtain permission directly from the copyright holder. To view a copy of this licence, visit http://creativecommons.org/licenses/by/4.0/.

antiretroviral drugs in the peripheral nervous system may increase this incidence. After entering into the brain, HIV follows both pathophysiologic infectious pathway and degenerative pathway [3]. As the immune system starts to deteriorate, neurological complications are seen and will finally result in dementia $[4,5]$. Novel therapies to treat inflammatory mechanisms can be effective [6]. Safe and effective drug delivery to the brain is essential to protect its structure and function [5, 7]. To develop validated bioanalytical methods and absolute animal models for brain pharmacokinetic study are thrust area of research for the brain targeted drug delivery systems.

There are several applications of HPLC in pharmaceutical analysis at different stages starting from the 


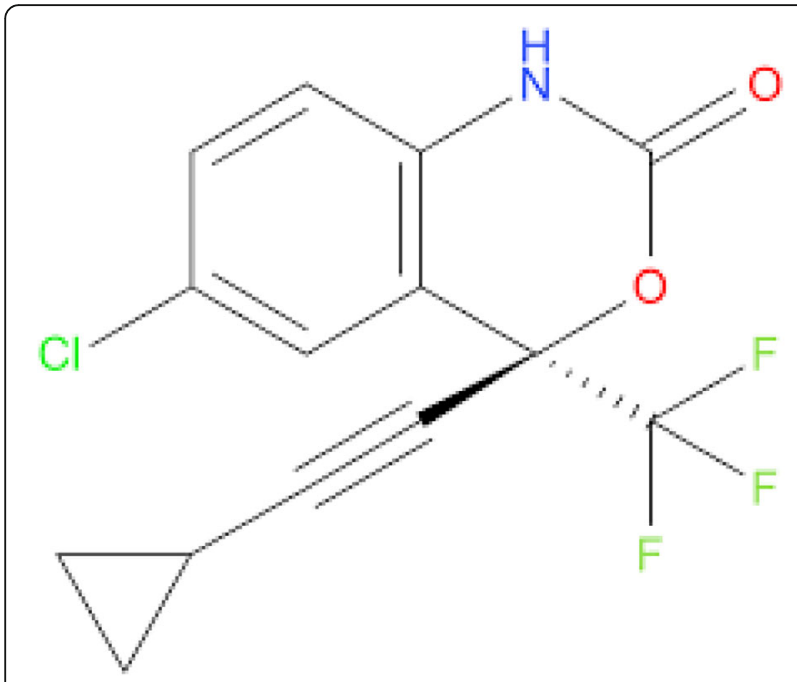

Fig. 1 Efavirenz structure

discovery of a new drug until it is ready to use for patients. HPLC technique is remarkable in the identification of drug targets and specific ligands by performing bioassay. In the RP-HPLC, less polar analytes could be retained by non-polar stationary phase for a longer time than polar ones; this principle was used in this work [8].

HPLC methods have been previously developed for the estimation of EFV in the plasma of patients on highly active antiretroviral therapy (HAART) [9]. The RP-HPLC method for EFV was developed and validated on human plasma $[9,10]$. Drug safety and effectiveness can be evaluated with validated methods to provide us supportive critical data [11]. Methods for analysis of EFV in human plasma could work out for plasma sample analysis, but brain pharmacokinetics can be established well with specific methods developed with brain models. In this research work, we made attempt for the same.

The following are the applications of the developed method:

1. Study of the pharmacokinetics of EFV in the brain after oral, nasal, or parenteral route of administration

2. Study drug targeting index of EFV for the brain targeted drug therapy; example: Neuro-AIDS treatment where the brain is the viral sanctuary site for HIV

3. Study of the toxicological potential of EFV in the different drug delivery approaches like nanoparticulate drug delivery, etc.

The RP-HPLC system has been used for the analysis of the antiviral agent with an ultraviolet (UV) detector. A novel perspective for the determination of the EFV in the brain is described in the paper. The entire analysis was performed as per the Bioanalytical Method Validation Guidance for Industry given by the US Department of Health and Human Services Food and Drug Administration [11].

\section{Methods}

\section{Chemicals and reagents}

Pure EFV sample was obtained as a gift sample from Mylan Laboratories, Sinnar, Nashik. HPLC grade solvents methanol and water were used as mobile phase in the analysis obtained from Thermo Fisher Pvt. Ltd. Solvents were degassed by sonication and then filtered through ultrafiltration unit prior to use.

\section{Instrumentation}

RP-HPLC (HPLC 3000 series) of Analytical Technology Pvt. Ltd. with a binary gradient system with a UV detector was used for analysis. C18 column (Cosmosil) was used for the HPLC analysis. Data were obtained and processed in the HPLC Workstation software. A sonicator (WUC-4L, WENSAR) was used for the degassing of the mobile phase. Cellulose membrane filter $0.45 \mu$ size (Borosil) was used. Tissue homogenizer and cooling centrifuge (Electrotechnik) were required for the processing of brain tissue. High-precision weighing balance-PGB 100 (Wensar) was used.

\section{Chromatographic conditions}

The optimized condition used was methanol to water in a ratio of 9:1 with a $0.8-\mathrm{mL}$ flow rate per minute. The wavelength for the detection was set at $248 \mathrm{~nm}$. The separation was carried out in a C18 Cosmosil column with $250 \mathrm{~mm} \times 4.6 \mathrm{ID}$, particle size $5 \mu$ dimension. The sample volume injected was $20 \mu \mathrm{L}$. Table 1 shows the optimum chromatographic conditions. The effectiveness of the theoretical plates was within 5000 to 10,000 while the tailing factor was less than 1.75. It ensures the performance of the analytical system.

\section{Sample preparation}

Stock solutions of EFV were prepared with the solvent in the same ratio of the mobile phase used for the

Table 1 Chromatographic conditions

\begin{tabular}{ll}
\hline Equipment & HPLC $\mathbf{3 0 0 0}$ series (Analytical Technology ) \\
\hline Mobile phase & Methanol to water (9:1) \\
Column & $\begin{array}{l}\text { C18 (Cosmosil) } 250 \mathrm{~mm} \times 4.6 \mathrm{ID}, \\
\text { particle size } 5 \mu \text { dimension }\end{array}$ \\
Column temperature & Ambient \\
Injection volume & $20 \mu \mathrm{L}$ \\
Flow rate & $0.8 \mathrm{~mL} / \mathrm{min}$ \\
Wavelength & $248 \mathrm{~nm}$ \\
Sample cooler & $5^{\circ} \mathrm{C}$ \\
\hline
\end{tabular}


validation at the concentration of $1000 \mu \mathrm{g} / \mathrm{mL}$ which was further diluted to $100 \mu \mathrm{g} / \mathrm{mL}$. Further dilutions were formed using the $100-\mu \mathrm{g} / \mathrm{mL}$ stock solution for the calibration curve in the range of 0.4 to $8 \mu \mathrm{g} / \mathrm{mL}$.

\section{Linearity}

The calibration curve for the linearity parameter of EFV was obtained by injecting solutions of the concentration ranging from 0.4 to $8 \mu \mathrm{g} / \mathrm{mL}$. The dilutions were prepared from the stock and the working solution of standard EFV of $1000 \mu \mathrm{g} / \mathrm{mL}$ and $100 \mu \mathrm{g} / \mathrm{mL}$, respectively. Quality control standards LQC of $1.2 \mu \mathrm{g} / \mathrm{mL}, \mathrm{MQC}$ of $4.8 \mu \mathrm{g} / \mathrm{mL}$, and HQC of $8 \mu \mathrm{g} / \mathrm{mL}$ were used. The calibration graph was plotted as the concentration of the drug solutions versus the peak area of each. The value of the slope, regression coefficient, and intercept were determined.

\section{Recovery}

Recovery was determined by calculating the amount of drug detected in the brain after the addition of the dose and was compared with that of the standard injected in the column.

\section{Accuracy}

Accuracy of the method was calculated by injecting the five replicates of the quality control standards of lower (LQC) $1.2 \mu \mathrm{g} / \mathrm{mL}$, medium (MQC) $4.8 \mu \mathrm{g} / \mathrm{mL}$, and higher (HQC) $8 \mu \mathrm{g} / \mathrm{mL}$. The abovementioned concentration or dose of LQC, MQC, and HQC was injected into the rat brain sample to perform the accuracy data. The rat brain was isolated, and the dose of the three concentrations was added separately into the brain samples which were processed and further injected in the HPLC column. After the analysis, the peak area was observed to calculate the standard deviation and percentage relative standard deviation.

\section{Sensitivity}

The sensitivity of the method was demonstrated as the limit of detection (LOD) and limit of quantification (LOQ) for EFV. LOD and LOQ can be calculated by using the standard deviation and the slope of the calibration curve. From the following formula, LOD and LOQ can be calculated:

$$
\mathrm{LOD}=3.3 \sigma / s \quad \mathrm{LOQ}=10 \sigma / s
$$

where:

$\sigma=$ standard deviation of the response

$s=$ slope of the calibration curve

\section{Specificity}

The specificity of the developed method was confirmed by analyzing the chromatogram of the standard EFV drug and the deproteinized brain extract. Both chromatograms were observed for any interference in the brain sample at the standard retention time of the EFV. This study was done to ensure the presence of impurities or proteins or plasma bio-matrix at the retention time of the EFV.

\section{Precision}

A random error that occurs in the method was considered as the precision parameter. The errors can be eliminated by analyzing the replicates of the observed results. The relative standard deviation (RSD) or the coefficient of variation of the analytical results were obtained from separately prepared quality control standards to evaluate the precision of the method.

\section{Extraction of drug from the brain}

For extracting the EFV from the brain, the following method was carried out.

The experimental procedures were conducted after the approval of the Institutional Animal Ethics Committee (IAEC) as per the guidelines of the CPCSEA for the care of laboratory animals. Male Wistar rats (250 g) were nourished with routine diet and water, ad libitum. Animals were acclimatized to an in-house animal facility for 1 week with a 12-h light/dark cycle and a temperature of $22 \pm$ $2{ }^{\circ} \mathrm{C}$. Ketamine $50 \mathrm{mg} / \mathrm{mL}$ IP (Ketamax 50) was used to induce anesthesia in the rat before the removal of the brain. The rat was sacrificed to isolate the brain. Brain tissue samples were homogenized in a homogenizer (T-25 IKA, Ultraturrex) in saline at 20,000 rpm for $5 \mathrm{~min}$. To the homogenized brain sample, EFV was added linearly in different concentrations for the calibration plot with the six points of $0.4 \mathrm{ppm}, 0.8 \mathrm{ppm}, 2.4 \mathrm{ppm}, 4.8 \mathrm{ppm}, 6.4 \mathrm{ppm}$, and $8 \mathrm{ppm}$ in six different isolated homogenized brain samples. This homogenized brain sample with the addition of the EFV was sonicated for $10 \mathrm{~min}$ [12-17]. Deproteinization of the sample was carried out by adding $5 \mathrm{~mL}$ of ethyl acetate which can be done by the addition of any non-polar solvent. Which further vortexed for 5 $\mathrm{min}$, after $5 \mathrm{~min}$, it was centrifuged in the cooling centrifuged at $1000 \mathrm{rpm} / 10 \mathrm{~min} / 4{ }^{\circ} \mathrm{C}$ to separate the organic layer which was transferred to the sample vial and allowed to evaporate to dryness. After complete evaporation, 10 $\mathrm{mL}$ of the mobile phase was added to the vial, sonicated properly, and injected in the HPLC column (C-18). The graph was plotted for linearity response.

\section{Stability studies}

Stability study of EFV in the brain was carried out for the short and long terms. Three quality control 
concentrations LQC, MQC, and HQC were analyzed in triplicates for the stability study. The four sets of the quality samples were prepared and placed in the sample vials and analyzed for the short-term and long-term stability study. One sample was analyzed freshly at the same time while the three were analyzed after $6 \mathrm{~h}, 12 \mathrm{~h}$, and $24 \mathrm{~h}$ of the preparation for the short-term study. The percent deviation was calculated. For the long-term study, one sample was analyzed freshly on the same day of preparation. The other three were analyzed on the 10th day, 20th day, and 30th day.

\section{Result}

\section{Linearity}

The calibration plot was obtained by injecting extracted drug from the brain into the HPLC column. The calibration curve is given in Fig. 2. The equation of the calibration curve is $y=21,023 x+14,253$. The regression coefficient was found to be 0.9867 which ensures the high precision of the developed method. Table 2 shows the data for the linearity. The spectrum for a blank sample of brain homogenate is given in Fig. 3. The spectrum for standards EFV is mentioned in Fig. 4. And Fig. 5 gives the presence of EFV in the brain homogenate.

\section{Accuracy}

The accuracy parameters were calculated by taking the quality control samples with low, medium, and high concentrations of the drug EFV (LQC, MQC, and HQC, respectively) with five replicates of each three concentration, i.e., $1.2 \mu \mathrm{g} / \mathrm{mL}, 4.8 \mu \mathrm{g} / \mathrm{mL}$, and $8 \mu \mathrm{g} / \mathrm{mL}$, respectively. The extraction was carried out in the same manner as mentioned above. Table 3 shows the values for accuracy.

\section{Recovery}

Recovery data was calculated by comparing the standard drug $4 \mu \mathrm{g} / \mathrm{mL}$ concentration with that of the brain

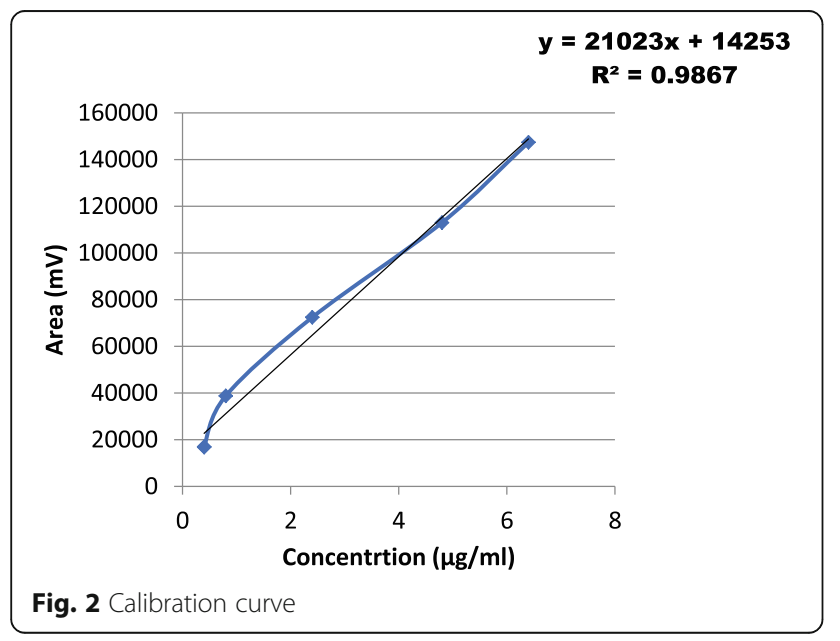

Table 2 Linearity ranges

\begin{tabular}{lll}
\hline Sample name & Sample Conc. $(\boldsymbol{\mu g} / \mathbf{m L})$ & Area $(\mathbf{m V})$ \\
\hline Standard A & 0.4 & $16,734 \pm 485.1979$ \\
Standard B & 0.4 & $16,927 \pm 330.5768$ \\
Standard C & 0.8 & $38,729 \pm 549.3806$ \\
Standard D & 2.4 & $72,371 \pm 1424.877$ \\
Standard E & 4.8 & $112,938 \pm 4922.987$ \\
Standard F & 6.4 & $147,364 \pm 1450.975$ \\
Standard G & 8.0 & $196,834 \pm 6006.519$ \\
\hline
\end{tabular}

sample. Added $4 \mu \mathrm{g} / \mathrm{mL}$ in the brain (extracted similarly as mentioned above) and calculated in the three replicates. Recovery was found to be nearly $78 \%$.

\section{Sensitivity}

The values of the LOD and the LOQ were found to be 0.1126 and 0.3414 , respectively.

\section{Stability studies \\ Short-term stability}

In the short-term study, the brain sample was kept at RT for three different time intervals which were 6,12 , and $24 \mathrm{~h}$. It is found that degradation was increasing over time. During $6 \mathrm{~h}, 32 \%$ degradation was observed, and at $12 \mathrm{~h}$, it was found nearly $53 \%$ while during $24 \mathrm{~h}$, it was $70 \%$.

\section{Long-term stability}

Long-term stability was done for the number of days ( 10 days, 20 days, and 30 days) to check the amount of degradation. It was observed that $98 \%$ degradation was seen during the course of 10 days.

\section{Discussion}

Rat is a widely used animal model in the preliminary in vivo studies of pharmaceutical formulation. For in vivo characterization of brain-targeted drug delivery systems, it is required to perform biodistribution study of the drug in the brain as well as CSF. For such experiments, highly sensitive analytical methods are required. After oral administration, a very small fraction of the drug reaches the brain due to physiological barriers, and hence, sensitive methods are required for the estimation of the quantities present from micro- to nanogram per milliliter. A low-dose EFV gives virologic failure, and high doses can cause CNS toxicity [14]. Thus, the developed method will help researchers in the evaluation of novel drug delivery systems to estimate the CNS EFV level. Penetration of antiretroviral in the brain is the current focus for the effectiveness of HAART and CART. Very scattered data were availed on ARV drug penetration into brain tissue [15]. EFV has limited 


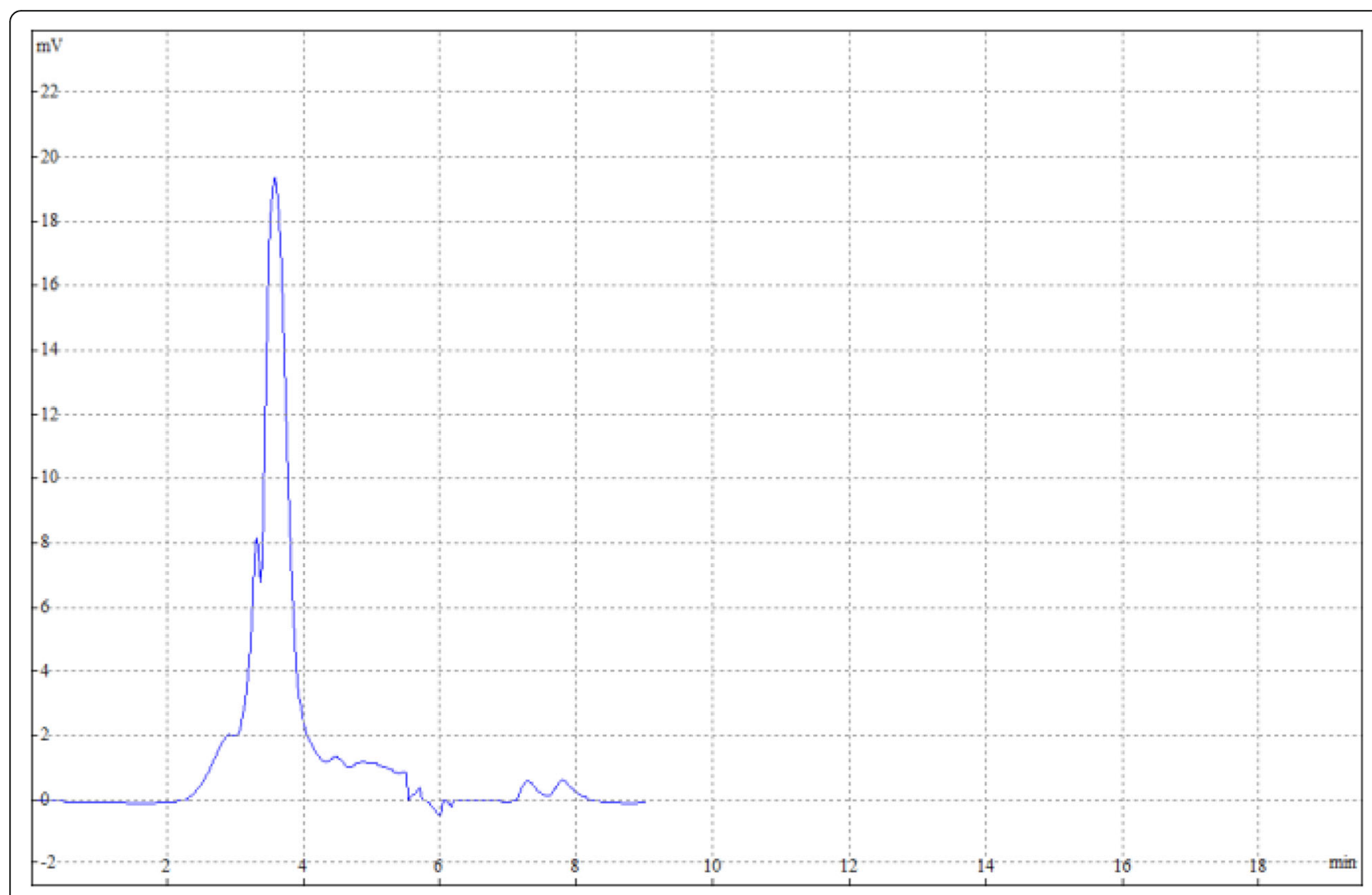

Fig. 3 Spectrum obtained for a blank sample of brain homogenate

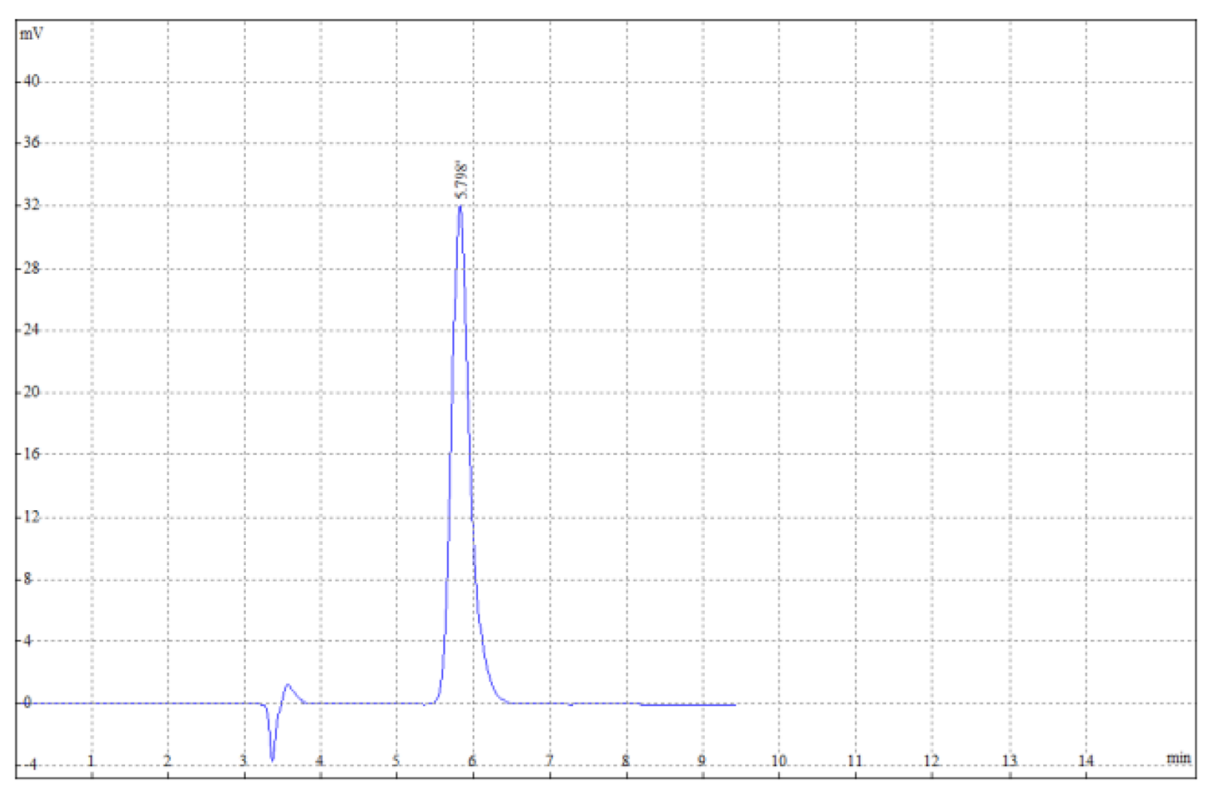

Fig. 4 Standard efavirenz spectrum 


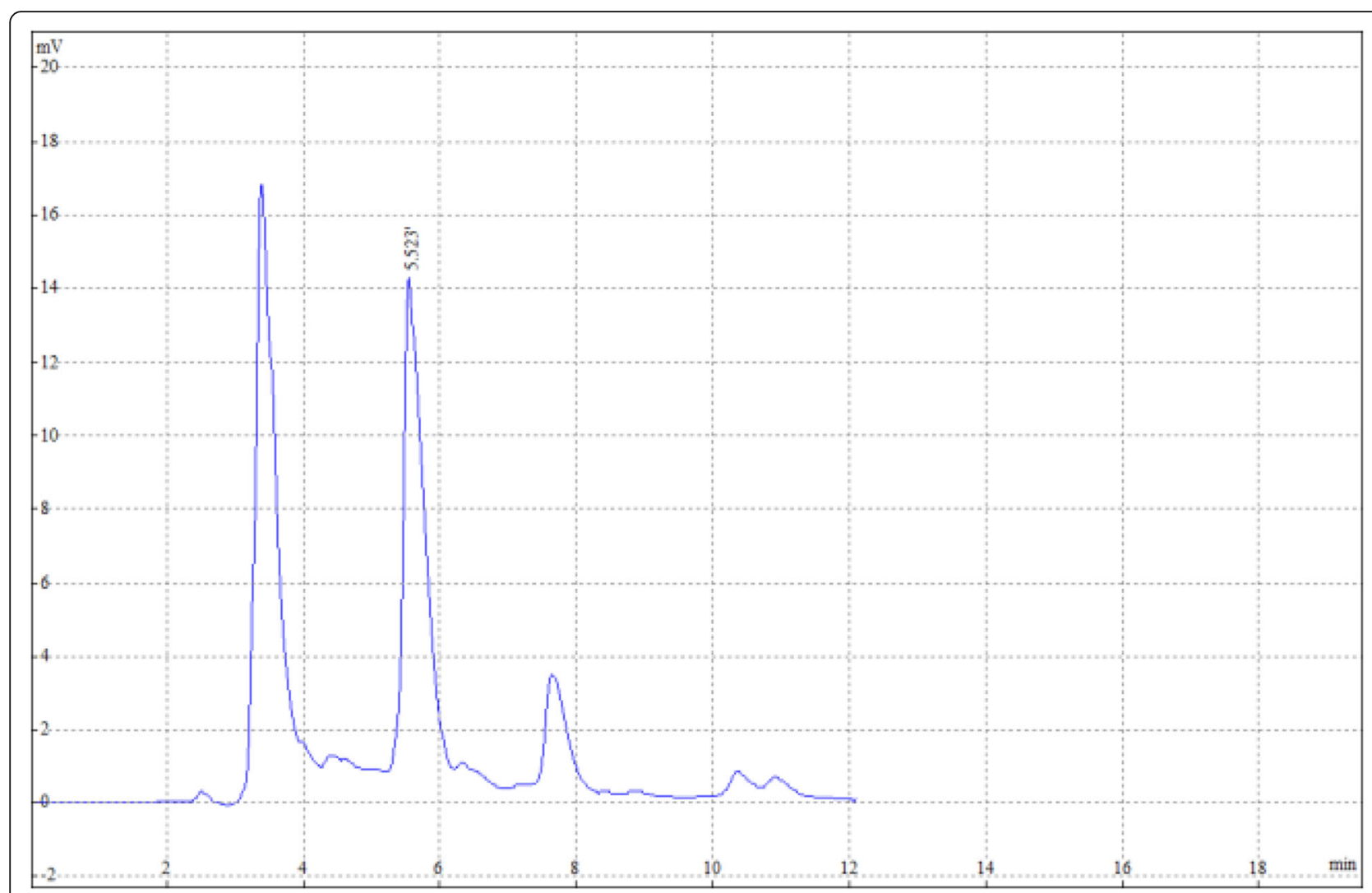

Fig. 5 Efavirenz in brain homogenate

central nervous system (CNS) penetration [16]. Thus, the developed method is suitable for the estimation of EFV in the rat brain.

\section{Conclusion}

Previously reported methods were for the estimation of EFV in the plasma. This method is for the estimation of brain EFV concentration in a rat model. It will be helpful for studying the brain targeting the index of EFV in the rat model and further pharmacokinetic estimation of EFV in the brain. We have developed a reliable method for the estimation of antiretroviral drug EFV in the rat brain, and it was found to be sensitive, specific, simple, and accurate. The system suitability parameters, \% RSD, recovery, and regression coefficient were found to be within the limit range. The developed method could be carried out in routine analysis as it is precise.

Table 3 Data for accuracy

\begin{tabular}{lll}
\hline Sample name & Sample Conc. $(\boldsymbol{\mu g} / \mathbf{m L})$ & Area $(\mathbf{m V})$ \\
\hline LQC & 1.2 & $56,117 \pm 717.9001$ \\
MQC & 4.8 & $116,927 \pm 1541.274$ \\
HQC & 8.0 & $197,239 \pm 3576.957$ \\
\hline
\end{tabular}

\section{Abbreviations}

EFV: Efavirenz; RP-HPLC: Reverse phase high-performance chromatography; NRTI: Non-nucleoside reverse transcriptase inhibitors; HAART: Highly active antiretroviral therapy; C-ART: Current antiretroviral therapy; RSD: Relative standard deviation; QCs: Quality control samples; IAEC: Institutional Animal Ethics Committee; CPCSEA: Committee for the Purpose of Control and Supervision of Experiments on Animals

\section{Acknowledgements}

The authors are grateful to MET Institute of Pharmacy for providing laboratory support.

\section{Authors' contributions}

SPK (main author and corresponding author of the research paper): concept, performed laboratory experiments, statistical analysis with graph, and prepared the final manuscript. SJK (co-author): supervised and monitored all the experiments and activities. All authors read and approved the final manuscript.

\section{Funding}

The study was done through self-finance.

\section{Availability of data and materials}

All data and materials are available upon request.

\section{Ethics approval and consent to participate}

The study was approved by the Institutional Animal Ethical Committee of METs Institute of Pharmacy, Nashik (Approval number MET-IOP-IAEC/201920/02), India.

\section{Consent for publication}

Not applicable 


\section{Competing interests}

The authors declare that they have no competing interests.

Received: 1 October 2020 Accepted: 15 December 2020

Published online: 07 January 2021

\section{References}

1. De Clercq E (2004) Non-nucleoside reverse transcriptase inhibitors (NNRTIs): past, present, and future. Chem Biodivers 1(1):44-64. doi: https://doi.org/10. 1002/cbdv.200490012

2. Usach I, Melis V, Peris J-E (2013) Non-nucleoside reverse transcriptase inhibitors: a review on pharmacokinetics, pharmacodynamics, safety and tolerability. J Int AIDS Soc 16(1):18567 https://dx.doi.org/10.7448\%2 FIAS.16.1.18567

3. Shapshak P, Kangueane P, Fujimura RK (2011) Editorial NeuroAIDS review. AIDS 25(2):123-141. https://doi.org/10.1097/QAD.0b013e328340fd42

4. Pereira C.F., Nottet H.S.L.M (2000) The blood-brain barrier in HIV-associated dementia. NeuroAids Volume 3(2). AAAS Science Publications, Inc. Database. http://aidscience.org/neuroaids/zones/articles/2000/03/BloodBrainBarrier/ index.asp Accessed 16 May 2020

5. Smita K, Sanjay K (2020) Neuro-AIDS: current status and challenges to antiretroviral drug therapy (ART) for its treatment. Current Drug Therapy 15(1). https://doi.org/10.2174/1574885515666200604123046

6. McArthur JC, Brew BJ, Nath A (2005) Neurological complications of HIV infection. Lancet Neurol 4(9):543-555. https://doi.org/10.1016/S14744422(05)70165-4

7. Smita K, Sanjay K (2019) Current nano drug delivery strategies available for nose to brain drug targeting. J Emerging Technol Innovative Res. 6(6): 778 -786. Database: http://www.jetir.org/papers/JETIR1907T84.pdf Accessed 26 Aug 2020.

8. Oona Mcpolin (2009) An introduction to HPLC for pharmaceutical analysis. In: HPLC analytical method. Mourne Training Services. United Kingdom. p 65

9. Langmann P, Schirmer D, Vath T, Zilly M, Klinker H (2001) High-performance liquid chromatographic method for the determination of HIV-1 nonnucleoside reverse transcriptase inhibitor efavirenz in plasma of patients during highly active antiretroviral therapy. J Chromatography B 755:151-156

10. Gupta S, Kesarla R, Chotai N, Omri A (2017) Development and validation of reversed-phase HPLC gradient method for the estimation of efavirenz in plasma. PLoS One 12(5):e0174777

11. Bioanalytical Method Validation Guidance for Industry, U.S. Department of Health and Human Services Food and Drug Administration Center for Drug Evaluation and Research (CDER) Center for Veterinary Medicine (CVM) May 2018 Biopharmaceutics available online at https://www.fda.gov/files/drugs/ published/Bioanalytical-Method-Validation-Guidance-for-Industry.pdf

12. Arti B, Shagufta K, Pramod Y (2018) Intranasal chitosan HP-B-CD nanoparticles of efavirenz for the CNS targeting. Artificial Cells Nanomed Biotechnol 46(02):374-386. https://doi.org/10.1080/21691401.2017/1313266

13. Erdő F, Bors LA, Farkas D, Bajza Á, Gizurarsons S (2018) Evaluation of intranasal delivery route of drug administration for brain targeting. Brain Research Bulletin doi. https://doi.org/10.1016/j.brainresbull.2018.10.009

14. Pailla SR, Talluri S, Rangaraj N et al (2019) Intranasal zotepine nanosuspension: intended for improved brain distribution in rats. DARU J Pharm Sci 27:541-555. https://doi.org/10.1007/s40199-019-00281-4

15. Marzolini C, Telent A, Decostered L et al (2001) Efavirenz plasma levels can predict treatment failure and central nervous system side effects in HIV-1infected patients. AIDS 15:1193-1194

16. Srinivas N, Joseph SB, Robertson K et al (2019) Predicting efavirenz concentrations in the brain tissue of HIV-infected individuals and exploring their relationship to neurocognitive impairment. Clin Transl Sci 12(3):302311. https://doi.org/10.1111/cts.12620

17. Avery LB, Sacktor N, McArthur JC, Hendrix CW (2013) Protein-free efavirenz concentrations in cerebrospinal fluid and blood plasma are equivalent: applying the law of mass action to predict protein-free drug concentration. Antimicrob Agents Chemother 57(3):1409-1414. https://doi.org/10.1128/ AAC.02329-12

\section{Publisher's Note}

Springer Nature remains neutral with regard to jurisdictional claims in published maps and institutional affiliations.

\section{Submit your manuscript to a SpringerOpen ${ }^{\circ}$ journal and benefit from:}

- Convenient online submission

- Rigorous peer review

- Open access: articles freely available online

- High visibility within the field

- Retaining the copyright to your article

Submit your next manuscript at $\boldsymbol{\nabla}$ springeropen.com 